\title{
Information support of intelligent energy systems and its impact on ensuring adequacy
}

\author{
Yuri Chukreyev ${ }^{1 *}$, Mikhail Chukreyev ${ }^{1}$ \\ ${ }^{1}$ Komi Scientific Centre of the Ural Branch of the Russian Academy of Sciences, ISE and EPN, 167000, Russia
}

\begin{abstract}
The issues of the influence of the changed conditions for obtaining probably-determined information on the operation of generating equipment and power consumption regimes on the decisions taken to ensure the required level of reservation of the territorial zones of the UES of Russia in the current regulatory environment to the indicators of balance reliability are considered. Comparison of the present conditions for presenting the initial information for the estimation of the balance sheet reliability of electric power systems with the conditions for the development of methodological recommendations (MR) for the design of power systems in 2003 and not approved by the Ministry of Energy of Russia MR 2012.
\end{abstract}

\section{Introduction}

The globalization of the electric power industry has led to the creation of unified energy systems (hereinafter referred to as "the EEC"). They connect the individual parameters of the regime of individual countries or their groups. An example is the Unified Energy System of Russia (hereinafter - UES of Russia), the unification of the power systems of the European Union, the unification of the power systems of North America. The reliability of the power balance of large EPS should be analyzed both in the whole system and in the context of its separate geographically allocated zones. In our country, within the framework of the Unified Energy System of Russia, there are zones in the form of integrated energy systems (UPS) with their fragmentation into separate territories. At the same time, the reliability of ensuring the power balance of each zone can be provided in different ways. In the European Union, the reliability of the power balance is ensured within each national energy system. In North America, 8 zones are identified (the habitable regions of the USA, Canada and Mexico). In them, the reliability of the power balance is ensured by both own sources and the generation of adjacent zones, but according to the previously agreed power supply rules. The feature of the UES of Russia is to ensure reliability both in North America, but without restrictions on the supply of power. By the mid-70s of the last century, a fairly strict hierarchical system was built on the basis of methods implemented in programs that make it possible to manage the development of the UES of the country for a perspective of 5 to 20 years. The task of ensuring balance reliability in this system has been given quite a lot of attention. This is necessary to justify the normative values of capacity reserves.
Reforming the industry in our country, started in the mid-1990s, led to a decrease in interest in issues of ensuring balance reliability when considering issues related to the long-term planning of the UES of Russia. This was facilitated by a number of factors: a sharp decrease in electricity consumption (by one third), a change in ownership patterns, deterioration in the quality of management personnel in the electricity sector, the closure of industry institutions and much more.

In the Federal Law "On Electric Power Industry" [1] the necessity of solving this problem was partially restored. The issues of justifying the means of ensuring reliability were legislatively assigned to the leading organization in the electric power industry of JSC "SO UES". Starting from 2009, in accordance with the Regulations approved by the RF Government Resolution ${ }^{* 1}$, JSC "SO UES" together with JSC "FGC UES" annually performs the work "Scheme and program for the development of the UES of Russia for a sevenyear period" (hereinafter - SaPD UES of Russia). We can say that from that time a new stage in the task of justifying the means of ensuring reliability under the management of the development of the UES of Russia began.

The importance of the problem of justifying the capacity reserves at the current stage of the country's electric power industry development is characterized by the assignment of Deputy Prime Minister A. Dvorkovich to the Ministry of Energy of Russia and the Ministry of Economic Development of Russia ${ }^{* 2}$ on the improvement of the long-term planning system in the electric power industry, UES of Russia. Below, the issues of

\footnotetext{
${ }^{* 1}$ Rules for the development and approval of schemes and programs for the future development of the electric power industry, approved by Government Decree No. 823 of October 17

${ }^{* 2}$ The original 8928 order of the government decree of 26.11.2016 for 5 liters.
} 
modernization of software complexes are considered in order to take into account the changed information content of the PBN assessment task and their impact on the decisions taken to justify the means of ensuring the reliability of the UES of Russia.

\section{Software product justification reserve capacity and upgrade to modern conditions}

The solution of the problem of the justification of normative power reserves and especially its compensation (operational) component required in the development of future balance of power. Their normalized values are justified in the preparation of methodical recommendations for the design of energy systems (MR) [2]. The rationale of capacity reserves is impossible without the development of software assessment indicators of adequacy. While developed in the post-Soviet period software is quite acceptable for modern conditions in terms of their methodological content. Currently, these include "Yantar" (ISEM SB RAS) [3] and "Orion-M" (ISE and EPN, Komi SC of the Ural branch of the RAS) [4]. The latter is more adapted to the changes. And more importantly he is more focused on the solution of the problem of the justification of power reserves. This software was used to design an MR 2003 and 2012, approved the Ministry of energy.

The software complex "Orion-M" is an upgrade of «Orion» [5]. It was widely used in the branches of the Institute "Energosetproekt" in the 80 s of the last century to analyze the balance reliability of prospective options for the development of EPS for 10-20 years. And in the beginning of 90 -ies was used to monitor the reliability of the UES of the former USSR for the accounting and for the next three years (JSC "NIIPT", now "STC UES"). In the period of reforming of the industry and the adoption of a Government resolution from 2009 to 2013 in "Orion-M" brought great changes [4]. They are to some extent influenced decisions on the justification of means of redundancy in the UES of Russia.

At the present stage the most appropriate indicators of adequacy from the standpoint of justification of the means of reliability, are:

- the probability of deficit-free operation of territorial zones of the EPS $\left(\rho=1-J_{\text {д }}\right)$, where $J_{\text {д }}-$ the integral probability of power shortage;

- the average number of days of power shortage (loss of the anticipated load - LOLE [6]);

- the average number of hours per year of power shortages (loss of load hours $-\mathrm{LOLH}$ ).

It should be noted that in the "Orion-M" provides for a wide range of indicators of adequacy, including all of the above.

\section{Upgrading software "Orion-M"}

The intellectualization of the power system in the aspect of obtaining reasonably reliable retrospective information about the generating and network equipment, and modes of consumption opens new opportunities for the methodological support of the objectives of adequacy. Statistical processing of information on the operation of generating equipment for a sufficiently long period of time allowed to identify certain trends in the change in the norms of their emergency planned repairs [4]. They are associated with the presence of huge untapped excess capacity [7]. Statistical processing of retrospective information on power consumption modes allowed to reveal the presence of correlation dependencies of random deviations from average hourly loads between individual territorial zones of the UES of Russia [8].

The above-mentioned factors have a significant impact on indicators of adequacy. Consequently, on their means of support and should be considered in the applied program complexes. All versions of "Orion" $[4,5]$ and other available [3], the formation of a deterministic random States at each discrete load change is carried out by statistical modeling methods (SM) (Fig.1).

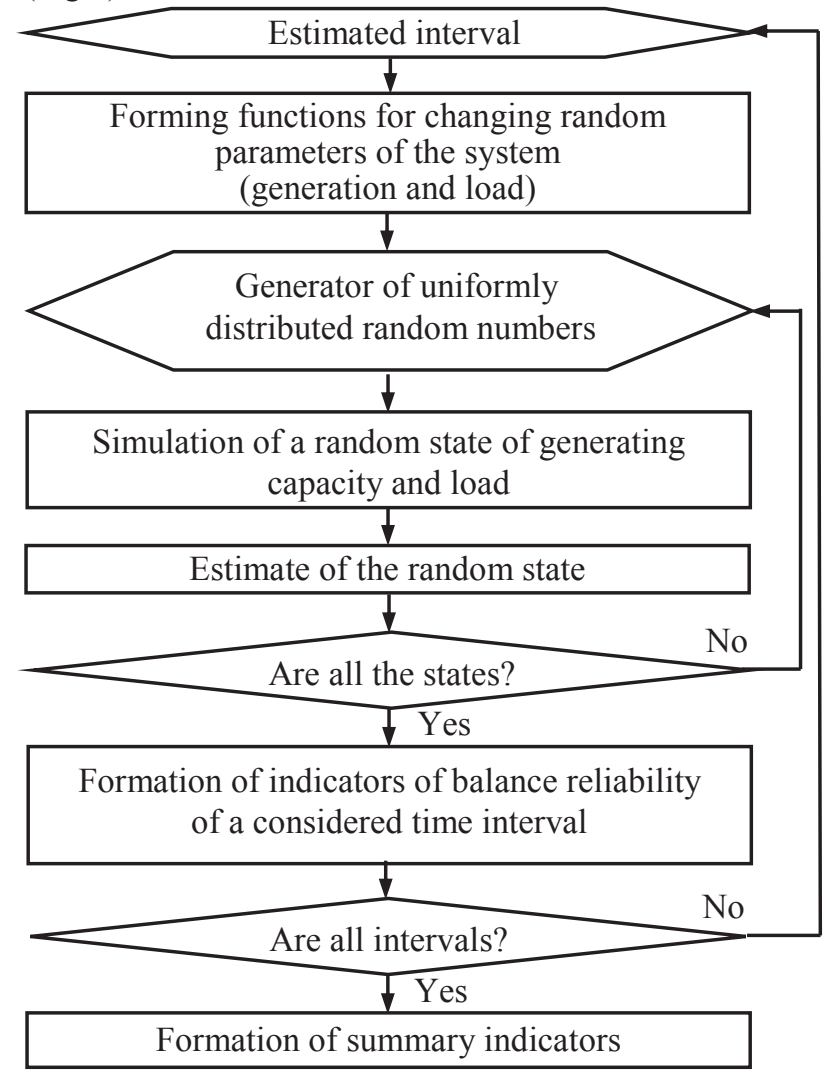

Fig. 1. Enlarged flowchart for estimating the balance reliability indicators of loading schedule intervals

Hitherto it was believed that random changes in the load in each territorial area variables are independent, both from the generation and loads of other areas. In this case, to increase the effectiveness of SM in a software was used, the composition of the distribution laws of random variables. In Fig. 2 shows the density ranges of probability decline in generating capacity $\left(f\left(P_{\mathrm{r}}\right)\right)$ and the random deviations of load $\left(f\left(P_{\mathrm{H}}\right)\right)$, and the composition of their distributions $\left(f\left(P_{\mathrm{c}}\right)\right)$. While $\mathrm{SM}$ is performed on the function tracks the distribution of generation and 
load $\left(F\left(P_{\mathrm{c}}\right)\right)$. Definition, subject only to a random value generation, the load remains constant and equal to the average degree of the graph $\left(\boldsymbol{P}_{\mathrm{H}}\right.$, Fig. 2).

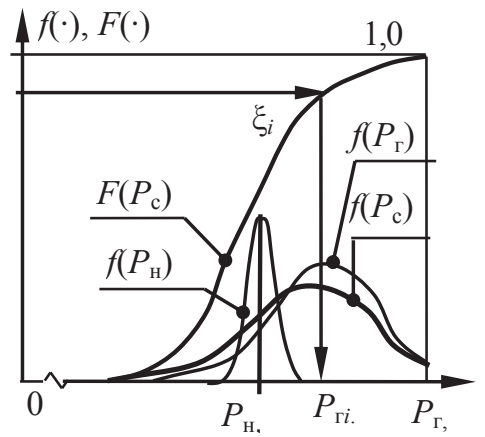

Fig. 2. The process of statistical modeling in "Orion-M"

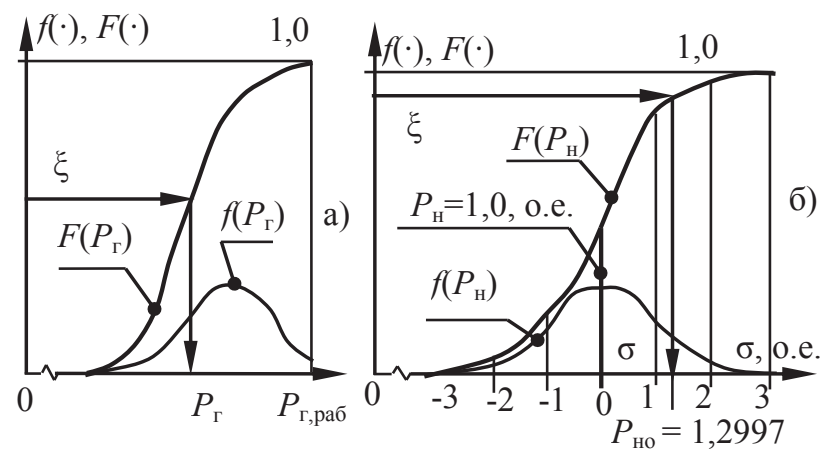

Fig. 3. Modernization of the process of statistical modeling: a) on generation, б) on the load

Account correlations of random fluctuations of the load at different territorial areas requires the implementation of the modeling process separately for the generating capacity and load (Fig. 3). Organization of the modeling process for existing generating capacity differs from the previous case. Instead of the function $F\left(P_{\mathrm{c}}\right)$ is applied $\left(F\left(P_{\mathrm{r}}\right)(\right.$ Fig. 3, a). To account for correlation of random fluctuations of load in different zones it is necessary to form the functions of their changes (under hypothesis of normal probability distribution law). The function is built in relative units, normalized to the average

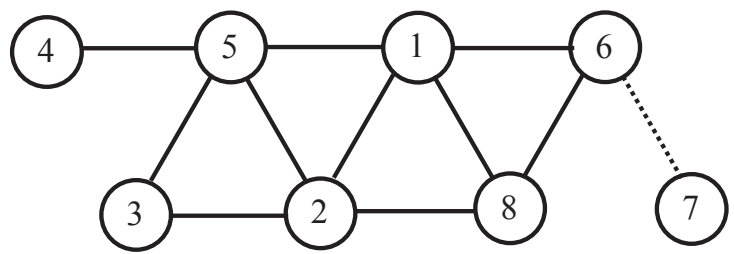

Fig. 4. Model of the settlement scheme of the UES of Russia. UPS: 1 - Ural; 2 - Average Volga; 3 - South; 4 Northwest; 5 - Center; 6 - Siberia; 7 - The Far East; 8 Kazakhstan.

quadratic deviation (the standard deviation $\sigma$, Fig. 3,б), Analysis of retrospective information, made in the [8] for the model design scheme of UES of Russia, represented in Fig. 4, allowed to form a correlation matrix $\boldsymbol{R}(1)$.

$$
\boldsymbol{R}=\left\|\begin{array}{cccccc}
1 & 0,71 & 0,54 & 0,50 & 0,58 & 0,68 \\
0,71 & 1 & 0,72 & 0,49 & 0,78 & 0,50 \\
0,54 & 0,72 & 1 & 0,23 & 0,53 & 0,30 \\
0,50 & 0,49 & 0,23 & 1 & 0,83 & 0,56 \\
0,58 & 0,78 & 0,53 & 0,83 & 1 & 0,47 \\
0,68 & 0,49 & 0,30 & 0,56 & 0,47 & 1
\end{array}\right\|
$$

In the modeling of random fluctuations of load by statistical modeling methods used decomposition of this matrix into factors by the method of Cholesky [9]. Then, the random vector of deviations of the power consumption from the average value is determined by the expression-statement $\Delta P=\sigma \times L r \times P_{\mathrm{H} 0} \quad\left(P_{\mathrm{H} 0} \quad-\right.$ simulated power load in p. u., in Fig. 3 equal 1,2997). At constant correlation matrix $\mathrm{R}$ matrix $\mathrm{Lr}$ takes the form presented in (2).

$$
\boldsymbol{L r}=\left\|\begin{array}{cccccc}
1 & 0 & 0 & 0 & 0 & 0 \\
0,708 & 0,706 & 0 & 0 & 0 & 0 \\
0,543 & 0,468 & 0,698 & 0 & 0 & 0 \\
0,503 & 0,193 & -0,188 & 0,821 & 0 & 0 \\
0,579 & 0,527 & -0,042 & 0,516 & 0,345 & 0 \\
0,679 & 0,019 & -0,108 & 0,235 & -0,186 & 0,66
\end{array}\right\|
$$

Let the methods of statistical simulation of the generated load vector with the values of power in relative terms: $P_{\mathrm{H} 0}=\{1,3204 ; 0,500 ;-0,766 ;-1,394 ; 1,2997 ;-1,3998\}$. A new vector $P_{\mathrm{H \sigma}}=L r \times P_{\mathrm{H} 0}$ given (2) takes the form $P_{\mathrm{H \sigma}}=$ $\{1,3204 ; 1,288 ; 0,4165 ;-0,24 ; 0,2102 ;-0,5059\}$. The transition to named units is performed according to the expression $P_{H j}=\bar{P}_{H_{j}}+P_{H \sigma} \Psi_{\sigma}\left(\bar{P}_{H_{j}}\right.$ - the average load of $j$-th zone in MW, $\sigma-$ the standard deviation load $j$-th territorial area in $\mathrm{MW}$ ).

\section{Analysis of the rationale of reserve revisions MR 2003 and $2012^{\star 3}$ years}

The authors involved in the calculations for the justification of compensatory reserve capacity in these MR. This was the basis to the study of the peculiarities of the methodical principles of assessment indicators of adequacy [7] is applied in the calculations. The results obtained for "Orion-M", made in 2011-12, agree rather well with the results obtained in accordance with the MR 2003 and Another was to be expected, since information components of generating equipment accidents and random deviations of load from its mean values show no significant change. Confirmation of what was said characterizes the table. 1 . It shows the value of the full reserve capacity, obtained in accordance with the MR 2003 and "Orion-M" in 2011-2012, For obvious

\footnotetext{
${ }^{* 3}$ MR on the design of power systems / JSC "Institute" Energosetproekt ", 2012 (approved by NP" NTS UES "in July 2012,
} but not approved by the Ministry of Energy of Russia). 
temporal reasons, the results given for the balance of power already held in 2012 (SaPD 2011-2017).

Table 1. The total reserve capacity for 2012

\begin{tabular}{|c|c|c|c|c|c|}
\hline & \multirow[b]{2}{*}{ है } & \multirow{2}{*}{ 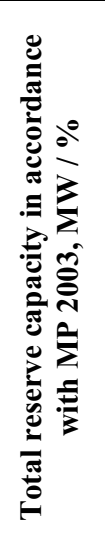 } & \multicolumn{3}{|c|}{$\begin{array}{c}\text { Estimated values of the total } \\
\text { reserve capacity (MW /\%) } \\
\text { when preparing the } 2012 \\
\text { MR }\end{array}$} \\
\hline & & & 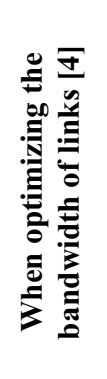 & 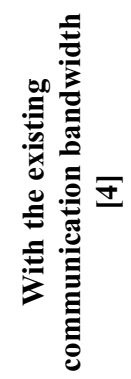 & 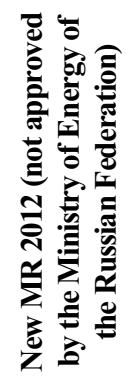 \\
\hline $\begin{array}{l}\text { UES of } \\
\text { Russia } \\
\text { without } \\
\text { East }\end{array}$ & $\begin{array}{l}147 \\
785\end{array}$ & $\begin{array}{l}23738 / \\
16,06\end{array}$ & $\begin{array}{l}24529 / \\
16,6\end{array}$ & $\begin{array}{l}22974 / \\
15,55\end{array}$ & $\begin{array}{l}30140 / \\
20,4\end{array}$ \\
\hline $\begin{array}{l}\text { UES of } \\
\text { Russia } \\
\text { (Europe } \\
\text { an part) }\end{array}$ & $\begin{array}{l}116 \\
945\end{array}$ & $\begin{array}{l}19881 / \\
17\end{array}$ & $\begin{array}{l}20241 / \\
17,31\end{array}$ & $\begin{array}{l}18980 / \\
16,23\end{array}$ & $\begin{array}{l}23340 / \\
19,93\end{array}$ \\
\hline Ural & $\begin{array}{l}350 \\
05\end{array}$ & $\begin{array}{l}6362 / \\
18,17\end{array}$ & $\begin{array}{l}6944 / \\
19,84\end{array}$ & $\begin{array}{l}6263 / \\
17,89\end{array}$ & $\begin{array}{l}7010 / \\
20\end{array}$ \\
\hline $\begin{array}{l}\text { Av. } \\
\text { Volga }\end{array}$ & $\begin{array}{l}173 \\
16\end{array}$ & $\begin{array}{l}2187 / \\
12,63\end{array}$ & $\begin{array}{l}2213 / \\
12,78\end{array}$ & $\begin{array}{l}15,07 / \\
8,7\end{array}$ & $\begin{array}{l}2860 / \\
16,5\end{array}$ \\
\hline South & $\begin{array}{l}140 \\
19\end{array}$ & $\begin{array}{l}1988 / \\
14,18\end{array}$ & $\begin{array}{l}2222 / \\
15,85\end{array}$ & $\begin{array}{l}2049 / \\
14,62\end{array}$ & $\begin{array}{l}2750 / \\
19,5\end{array}$ \\
\hline $\begin{array}{l}\text { Northwe } \\
\text { st }\end{array}$ & $\begin{array}{l}141 \\
51\end{array}$ & $\begin{array}{l}2982 / \\
21,07\end{array}$ & $\begin{array}{l}2815 / \\
19,89\end{array}$ & $\begin{array}{l}2933 / \\
20,73\end{array}$ & $\begin{array}{l}2700 / \\
19\end{array}$ \\
\hline Centre & $\begin{array}{l}364 \\
54\end{array}$ & $\begin{array}{l}6362 / \\
17,45\end{array}$ & $\begin{array}{l}6046 / \\
16,59\end{array}$ & $\begin{array}{l}6229 / \\
17,09\end{array}$ & $\begin{array}{l}8020 / \\
22\end{array}$ \\
\hline Siberia & $\begin{array}{l}308 \\
40\end{array}$ & $\begin{array}{c}3857 / \\
12,51\end{array}$ & $\begin{array}{l}4291 / \\
13,91\end{array}$ & $\begin{array}{l}3994 / \\
12,94\end{array}$ & $\begin{array}{l}6800 / \\
22\end{array}$ \\
\hline
\end{tabular}

In lines 3 and 4 of the table. 1 shows the value of the full reserve capacity, obtained by [10]. In the calculations of the norms for carrying out planned repairs of generating equipment and strategic reserve capacity have not changed significantly compared with the MR 2003 were considered two scenarios for the capacity of the links. One without optimization (line 4), the second with optimization for equal unit costs in the development of one $\mathrm{kW}$ of generating capacity and reserve capacity of the links (line 3).

In the 2012 edition of the MR magnitude of repair and the strategic power reserves adjusted by the Customers of the work of JSC "so UES" and JSC "Institute "Energosetproekt" (line 5 of the table. 1) [10]. Maintenance reserve main causes are the transition to a conclusion in repair of the condition as well as opened due to a reduction of power consumption, the possibility of medium and capital repairs in the winter time, including the month of December. These circumstances when processing the retrospective information has led to a significant increase in the proportion of fixation of reserve capacity. For information in the former Soviet Union reserves for capital repairs of virtually all of
United energy systems was zero. Rules for the strategic reserve in all of United energy systems was increased from $1-2 \%$ to $3 \%$ [10].

\section{The impact of information support of modern smart grids on the justification of power reserve}

In this section the results justify the compensation of reserve capacity in relation to the forecasted 2022 in accordance with SaPD UES of Russia in 2016 to 2022. Since the development is not approved by the Ministry of energy MR 2012 has been quite a dramatic change in the content objectives of the evaluation indicators, the carrying of reliability of the UES of Russia. This requires an estimation of the impact of these changes on decision-making on justification of compensation (operational) power reserve. Under content we understand statistical information about the generating equipment (unplanned and planned conclusions in repair) and probabilistic specific information about the deviations of load from its time of change for the average daily schedule of the month of December [8].

Table 2. Average statistical indicators of the location of generating equipment in emergency and scheduled repairs as a percentage of the irregular maximum load

\begin{tabular}{|c|c|c|c|c|c|c|c|c|}
\hline \multirow[b]{2}{*}{ № } & & \multirow[b]{2}{*}{$\begin{array}{c}\text { UES of } \\
\text { Russia } \\
\text { without } \\
\text { East }\end{array}$} & \multicolumn{6}{|c|}{ Name UPS } \\
\hline & & & $\begin{array}{c}\text { U } \\
\text { ra } \\
\text { I }\end{array}$ & \begin{tabular}{|c|}
$\mathbf{A}$ \\
$\mathbf{v}$ \\
$\mathbf{V}$ \\
$\mathbf{o l}$ \\
ga
\end{tabular} & $\begin{array}{l}\text { So } \\
\text { ut } \\
h\end{array}$ & $\begin{array}{c}\mathrm{N} \\
\text { or } \\
\text { th } \\
\text { we } \\
\text { st }\end{array}$ & $\begin{array}{l}\text { C } \\
\text { en } \\
\text { tr } \\
\text { e }\end{array}$ & $\begin{array}{l}\mathrm{Si} \\
\text { be } \\
\text { ri } \\
\text { a }\end{array}$ \\
\hline \multirow{2}{*}{1} & 2022 & 4,42 & 5,88 & 2,84 & 3,96 & 4,62 & 3,03 & 5,48 \\
\hline & MR 2012 & 5,99 & 6,67 & 5,36 & 5,26 & 7,22 & 6,91 & 4,38 \\
\hline \multirow{2}{*}{2} & 2022 & - & 4,09 & 3,27 & 4,68 & 4,82 & 3,89 & 4,07 \\
\hline & MR 2012 & - & 2,59 & 3,82 & 3,85 & 4,06 & 2,52 & 2,88 \\
\hline \multirow{3}{*}{3} & 2022 & 8,87 & 10,8 & 9,72 & 4,80 & 7,40 & 6,70 & 11,8 \\
\hline & MR 2012 & 6,80 & 5,30 & 7,50 & 3,90 & 4,40 & 8,30 & 9,00 \\
\hline & MR 2003 & & 4,91 & 2,65 & 3,00 & 4,91 & 6,24 & 3,09 \\
\hline 4 & $\begin{array}{l}\text { Irregular } \\
\text { load } \\
\text { maximum, } \\
\text { MW }\end{array}$ & 155860 & 37390 & 17096 & 16831 & 15151 & 39266 & 30126 \\
\hline
\end{tabular}

Their larger characteristics as a percentage of the irregular maximum load is given in table. 2. Comparison subject information about the random parameters of the system, recent and relevant information used in the preparation of MR 2012 and 2003, as reflected in the literature. For these sections the content of tasks in the rows of the table. 2 shows:

- first - mathematical expectation (m.e.) output in unscheduled emergency repairs of the generating equipment;

- second - random characteristics the medium quadratic deviation load percentage;

- the third - value of capacity reserves for planned repairs;

- in the fourth - magnitude irregular highs loads 2022 in accordance with SaPD UES of Russia in 2016-22. 
The table shows clearly significant changes in the random parameters of the generating equipment operation and the deviations in the power consumption regime that have occurred since the development of the MR 2012, as a result of the statistical processing of retrospective information in [8] (lines 2 and 3). A significant increase in the share of generating equipment that is in scheduled repair (line 4), as well as practically unused due to the presence of excess capacity, makes it necessary to conduct studies on their accounting when simulating emergency outputs of equipment for repairs. In Table. 3 presents the results of the influence of the noted changes in the information content of modern intellectualized EPS on the amount of the compensation power reserve.

Table 3. The values of the compensation capacity reserve for 2022 (MW /\%)

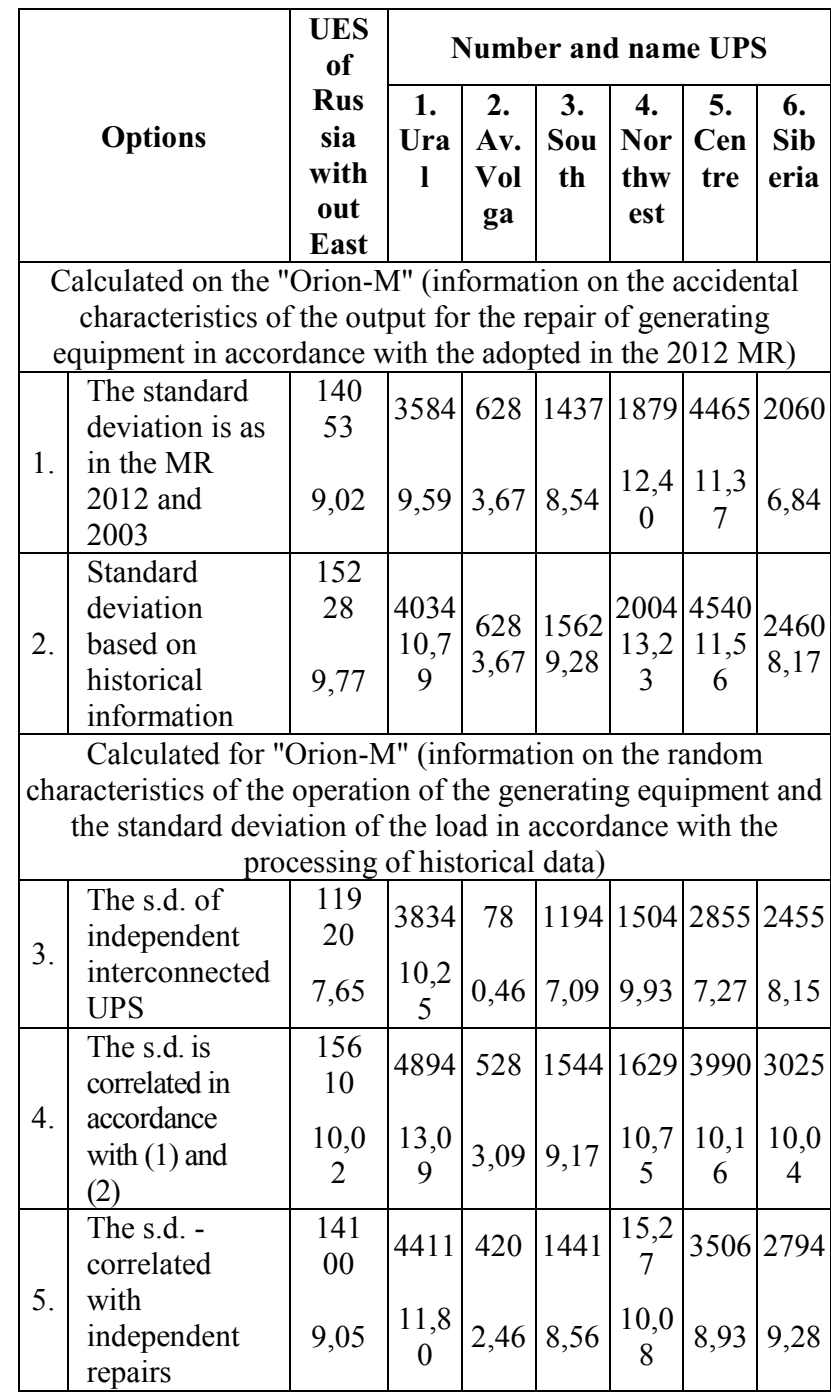

The first two positions of the table. 3 show the performance effect of energy consumption on the means of ensuring the reliability of the assumption of independence of random fluctuations of load in the form of standard deviations. The information about the accident generating equipment for cleanliness of experiment adopted in accordance with the requirements of MR 2012 (reference books). It was expected that in accordance with row 3 of the table. 2, the effect of random fluctuations of the load of the means of ensuring the reliability should be more important. However, in practice it is seen from table 3 this is not entirely confirmed.

A more significant discrepancy in the results justify the means of ensuring the reliability observed on the two following items in the table ( 3 and 4 ). Them for the same information about the random generation of hardware (from retrospective information) considered two approaches to the modeling of random fluctuations of load. First, as in the formation of the MR 2003 and 2012 (row 3). The second (line 4), taking into account the dependence of the random deviations between the UPS (see section 2). It can be seen that taking into account the correlation leads to a significant increase in the share of the compensation capacity reserve for the UES of Russia as a whole from 7.65 to $10.02 \%$.

Note that the compensatory reserve capacity for UES of Russia as a whole (line 3), using data on the state of generating equipment based on the processing of retrospective decreased by $2.22 \%$ compared to its value when using the same information from the reference data (line 2). This is consistent with the first row of the table. 2 , where the mathematical expectation of output in unscheduled repairs of generating equipment for the UES as a whole differ for these calculations, more than half of the item $(4,42$ and $5.99 \%)$. More significant decrease of compensatory reserve capacity $(2.22 \%)$ is easily explained by the reduction not only of the expectation of unscheduled repairs of the equipment, but also the dispersion of the distribution density $f\left(P_{\mathrm{r}}\right)$ (Fig. 2 and 3). For UES of Russia these changes is shown in Fig. 5. For each Union has consistently presented the mathematical expectation of unplanned insights generating equipment in repair and the necessary amount of the compensation allowance when using retrospective information. And these same settings, but using data on the generating equipment in accordance with reference books, as in MR 2012. In all member States except the Middle Volga, there is a strong correlation - the expectation is always less compensatory reserve. In the Middle Volga, the picture is somewhat different and this can be explained by the presence of this significant energy system reserves bandwidth connections with a sufficiently large capacity of the UPS Centre and the Urals (Fig. 4).

Apart in the study presented results (line 5), obtained taking into account the actual reduction in generating capacity by the magnitude of planned repairs of equipment and strategic reserve (terminal equipment). This required major modifications to "Orion-M". Modified the principles of simulation random variable generation and loads, and methods of forming the distribution function $F\left(P_{\mathrm{r}}\right)$ (Fig. 2 and 3). This has affected the composition of equipment is really involved in the coating loading (without components in planned repairs and the needs of the strategic reserve). The magnitude of compensatory reserve capacity for UES of Russia as a whole fell by almost one point (from 10.02 to $9.05 \%$ ). In separate energy systems of UES of Russia 
the decrease is also observed that fluctuation from 0.61 $\%$ (South) to $1.29 \%$ (Urals).

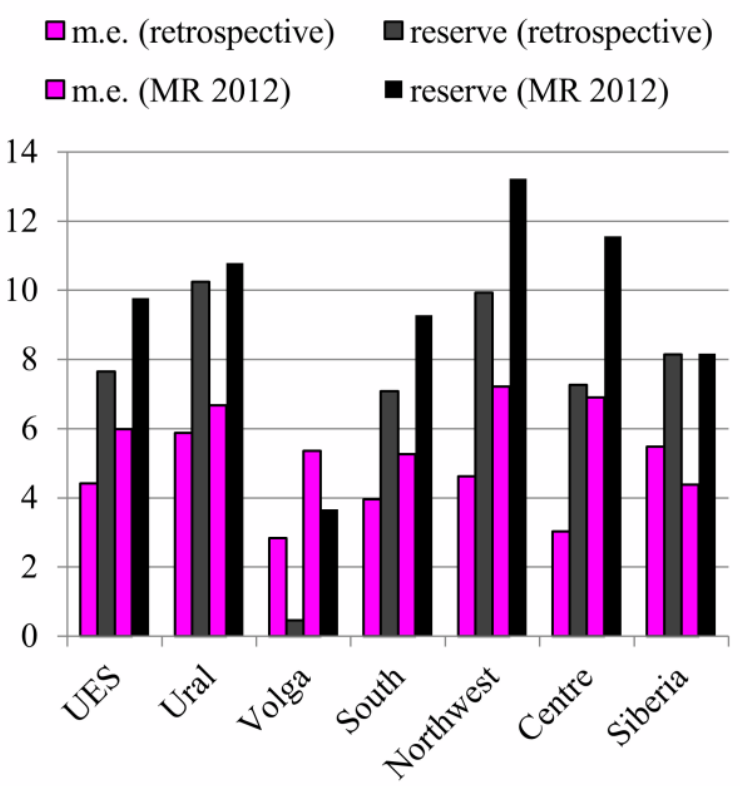

Fig. 5. Interrelation of changes in the random parameters of the power systems of the unit and calculated parameters of the compensation power reserve

In the last two rows (4 and 5) I would like to mention another important fact. Accounting the influence of random deviations of load between separate power systems of the UES of Russia dramatically (by 5-7 times) reduces the probability of over-bandwidth links in comparison with the assumption of independence of these deviations (row 3). This is further evidence of the unreliability of calculations on a substantiation of reserves bandwidth connections. They must first be determined by ensuring static and dynamic stability of power systems and transfer of large amounts of power due to the presence of different timing of the passage of the maximum load a separate grid UES of Russia.

\section{Conclusion}

Intellectualization UES of Russia, basing on analysis of retrospective information to identify the dependence of the random deviations of load between separate power systems within UES of Russia. Generate new performance standards for unplanned and planned repairs of generating equipment. This has led to the need to modernize the software and carry out comparative calculations on a different informational basis. Studies have shown the versatility of existing software ("Orion$\mathrm{M}^{\prime \prime)}$, the possibility of its adaptation to changing conditions, as a methodological and information aspect.

\section{References}

1. Federal Law "On Electric Power Industry" of March 26, 2003 No. 35-03.

2. Methodical recommendations on the design of power systems. Approved by the order of the Ministry of
Energy of Russia of June 30, 2003, No. 281 (Ministry of Energy of Russia, 2003)

3. G.F. Kovalev, L.M. Lebedeva Reliability of power systems (Novosibirsk: Science, 2015)

4. Yu.Ya. Chukreev, M.Yu. Chukreev Models for estimating the balance reliability indicators for managing the development of electric power systems (Syktyvkar, Komi Scientific Center of the Ural Branch of the Russian Academy of Sciences, 2014)

5. Yu.Ya. Chukreev Models for ensuring the reliability of electric power systems (Syktyvkar, Komi scientist. Center of UrO RAN, 1995)

6. R. Billinton, R.N. Allan Reliability Evaluation of Power Systems. Second Edition. (New York and London, Plenum Press, 1996)

7. Yu.Ya. Chukreev, M.Yu. Chukreev Energy Policy. Issue 2. - P. 39-50 (2017).

8. Report on R \& D "Substantiation of the normative values of the components of the total reserve capacity in the context of the UPS and UES of Russia as a whole in the planning of their development" (Syktyvkar, Komi Scientific Center of the Ural Branch of the Russian Academy of Sciences, 2016)

9. V.M. Verzhbitsky Fundamentals of numerical methods (Moscow, High School, 2009)

10. Report on research "Correction of methodological recommendations for the design of the development of power systems" (Moscow, JSC "Institute" ENERGOSETPROEKT", 2011) 